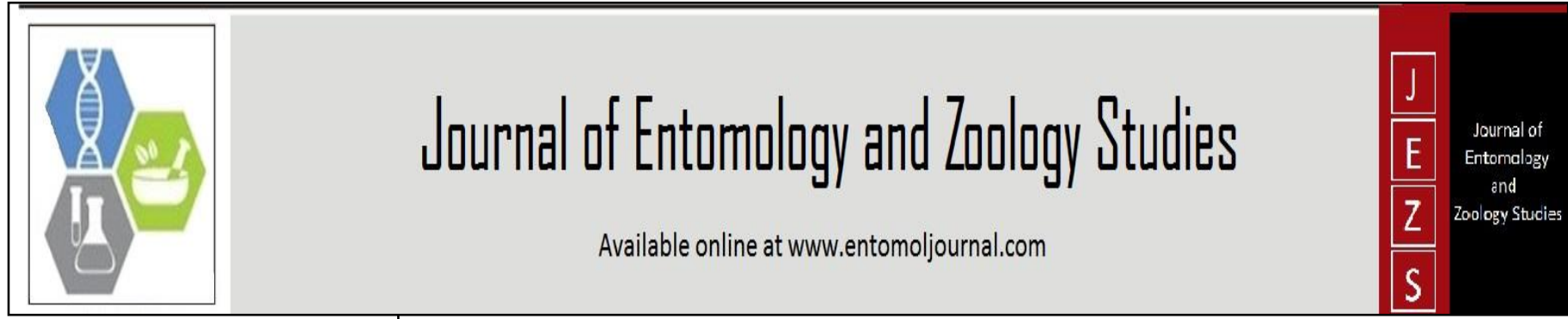

E-ISSN: 2320-7078

P-ISSN: 2349-6800

www.entomoljournal.com JEZS 2021; 9(1): 140-145 (C) $2021 \mathrm{JEZS}$

Received: 23-11-2020

Accepted: 25-12-2020

Nasrul I Shaikh

Research Scholar, Department of Biotechnology, College of Animal Biotechnology, Guru Angad Dev Veterinary and Animal Sciences University, Ludhiana, Punjab, India

RS Sethi

Professor and Head, Department of Animal Biotechnology, College of Animal Biotechnology, Guru Angad Dev Veterinary and Animal Sciences University, Ludhiana, Punjab, India
Corresponding Author: RS Sethi

Professor and Head, Department of Animal Biotechnology, College of Animal Biotechnology, Guru Angad Dev Veterinary and Animal Sciences University, Ludhiana, Punjab, India

\section{Differential gene expression profile of mice lung following chronic dietary exposure to chlorpyrifos and/or cypermethrin}

\section{Nasrul I Shaikh and RS Sethi}

DOI: https://doi.org/10.22271/j.ento.2021.v9.i1b.8139

\begin{abstract}
Chlorpyrifos is an organophosphate and the cypermethrin is Type 2 pyrethroid insecticide that are frequently used for indoor and outdoor pest control. The combination of both chlorpyrifos and cypermethrin is commonly used to control pest and prolonged exposures of this combination results in chronic or persistent neurologic and teratogenic effects along with abortions and other reproductive failure. We have earlier reported that delay exposure to cypermethrin and chlorpyriphos results in lung injury, however, the molecular mechanism remains to be elucidated. The present study was designed to study differential transcriptional profiling to identify the candidate genes associated with lung injury after exposure to chlorpyriphos and/or cypermethrin in a mouse model. Swiss male albino mice $(\mathrm{N}=24)$ ageing 6-8 week were divided into one control group and three treatment groups $(\mathrm{n}=8 \mathrm{each})$. Treatment group-I, II and III were given orally chlorpyriphos $(2.76 \mathrm{mg} / \mathrm{kg})$, cypermethrin $(2 \mathrm{mg} / \mathrm{kg})$ and combination dissolved in corn oil for 90 days. Lung samples were collected and subjected to microarray analysis. The data revealed that 365 genes were dysregulated following exposure to chlorpyrifos, cypermethrin and their mixture. Treatment with chlorpyriphos upregulated 194 genes and downregulated 171 genes whereas cypermethrin treatment caused upregulation of 171 genes and downregulation of 152 genes while their combination upregulated 176 genes and downregulated 146 genes (minimum cut off of 12.0 log fold change). Atp5g2, Cox6a1, Tpt1, Hint1, Fau, Rps27, Fth1, Rplp0 Sftpd and Sftpa were among the top ten dysregulated genes in all the treatments groups. Protein-protein interaction analysis showed that Atp5g2, Cox6a1, Tpt1, Hint1, Fau, Rps27, Fth1 and Rplp0 forms a network with each other whereas Sftpd and Sftpa1 are co- expressed. Data taken together suggest that exposure to chlorpyrifos and/or cypermethrin may induce lung damage via dysregulating the expression of Atp5g2, Cox6a1, Tpt1, Hint 1 , Fau, Rps27, Fth1, Rplp0, Sftpd and Sftpa.. The findings of current study have significance as farm workers get frequent exposures to the cocktail of these pesticides in field situations.
\end{abstract}

Keywords: Chlorpyrifos, cypermethrin, lung injury

\section{Introduction}

Indian agriculture sector is one of the largest agricultural producer around the globe thus, it is a vital asset for the economic development ${ }^{[1]}$. However, the country suffers from approximately $45 \%$ of production loss amounting to Rs 6,000 crores each year because of pest infestation. A wide range of pesticide are used to oppose pest and to enhance the agriculture yield ${ }^{[2]}$. The unrestrained pesticide usage is increasing in developing and developed countries and can be attributed to demand of crop production from the limited agriculture land ${ }^{[3,4]}$. The pesticide used against pest infestation are synthetic, persistent and ubiquitous in nature ${ }^{[5]}$. Extensive use of pesticides in agriculture has posed havoc to the mankind and environment due to their high rate of bioaccumulation and toxicity ${ }^{[6]}$. Dietary exposure is among the most common route of pesticide exposure ${ }^{[7]}$. Cypermethrin and chlorpyrifos are popular pesticide that belong to organophosphate and synthetic pyrethroids ${ }^{[8]}$. Cypermethrin, synthetic pyrethroid, is an insecticide and one of the most common environmental pollutants due to its extensive use against pest infestation at agriculture and domestic level ${ }^{[9]}$. Chlorpyrifos is the most commonly utilized insecticide in domestic vegetables ${ }^{[10]}$ and found to be is easily absorbed by organ surface such as intestine and lung ${ }^{[11]}$.

Lung is the first organ to come in contact with after inhalation of pesticides ${ }^{[12]}$. We have earlier reviewed ${ }^{[13,14]}$ and reported lung injury following exposures to imidacloprid ${ }^{[15,16] \text {, }}$ fipronil ${ }^{[17,18,19]}$, lindane ${ }^{[20]}$, indoxacarb ${ }^{[21,22]}$, chlorpyrifos ${ }^{[23]}, 2,4-\mathrm{D}^{[24,25]}$ and ethion ${ }^{[26,27,28]}$. The pulmonary impairment due to organophosphate causes alveolar congestion ${ }^{[29]}$, 
hemorrhage, neutrophil infiltration [30], emphysematous changes and cellular aggregation in vascular walls or air spaces ${ }^{[310,32]}$. Cypermethrin causes oxidative stress ${ }^{[33]}$ and developmental neurotoxicity ${ }^{[33]}$, cellular infiltration, necrotic changes, thickening of alveolar septa and inflammation of lung tissues. The synergistic effect of chlorpyrifos and cypermethrin has shown to cause lung damage in mice ${ }^{[35]}$.

However, there is no transcriptomic data available on the lung following long term dietary exposure to chlorpyrifos and cypermethrin individually or in combination. Hence, the current study was aimed to investigate transcriptomic profile of the mice lung in order to identify the differentially expressed genes exposed to chlorpyrifos and/or cypermethrin.

\section{Methods}

\section{In vivo experiments}

The experiment has been conducted as per approved protocol of institutional animal ethics committee (CPCSEA), Guru Angad Dev Veterinary and Animal Sciences University, Ludhiana. A total 24 albino Swiss male mice ageing 6-8 weeks were purchased from the disease free small animal colony maintained by Lala Lajpat Rai University of Veterinary and Animal Sciences, Hisar Haryana. Mice were acclimatized for a period of one week. Mice were weighed and divided randomly into 4 groups $(n=6)$ in polypropylene cages at institutional small animal house under controlled condition with $12 \mathrm{~h}$ light and dark cycle. Animals were fed synthetic pelleted mice feed obtained from Ashiward feed industries, Chandigarh and water ad libitum.

\section{Experimental design}

Animals were randomly divided into three treatment groups that received either cypermethrin (cypermethrin @ $2 \mathrm{mg} / \mathrm{kg}$ ) or chlorpyriphos@2.76mg/kg or their mixture orally dissolved in corn oil for 90 days. The control group received corn oil for 90 days. Immediately after the experiment, all animals were euthanized with xylazine and ketamine combination (Xylazine @ $0.5 \mathrm{ml} ; 20 \mathrm{mg} / \mathrm{ml}$ mixed with Ketamine @ 2ml; $50 \mathrm{mg} / \mathrm{ml}$ ) intraperitoneally.

\section{Tissue collection}

Lung tissue was collected in $2 \mathrm{ml}$ tube Rnase free centrifuge tube containing 1ml RNA later (Ambion, Austin, TX,USA) and stored at $-80^{\circ} \mathrm{C}$ and were subjected to RNA isolation for transcriptional analysis.

\section{Microarray gene expression and analysis}

About 50mg of lung tissue was used from each animal to extract RNA using Trizol method (Ambion, Life Technologies, USA). The quality of the isolated RNA was determined in Agilent 2100 Bioanalyzer as per manufacturer's protocol using the Agilent RNA 6000 Nano Kit. The RNA samples with an RNA integrity > 7 were selected for microarray hybridization. Low input quick Amp WT labeling Kit was used to label 100ng of total RNA as per manufacturer's protocol. RNA samples of three mice from each group were pooled into two biological replicates and one color microarray based exon analysis were performed in duplicates using two mouse microarray slides $(8 \times 60 \mathrm{~K}$ : Agilent - 028005). The quality check of labelled cRNA was performed by NanoDrop. The signal intensities were extracted after generation of the microarray scan images using Feature extraction software version 10.7.3. The obtained microarray data were analyzed to identify the differentially expressed genes (DEGs) with cut off of $12 \log$ fold change using DAVID online Bioinformatic tool(https://david.ncifcrf.gov/tools.jsp).

\section{Pathway analysis and functional Annotation}

David bioinformatic tool was used to perform the analysis of the DEGs with cut off of 12 . Gene ontology (GO) enrichment analysis of the top 10 Differently expressed genes were then conducted to investigate the biological processes enriched in the different experimental groups. Four categories of gene ontology i.e, biological process, cellular component, molecular function and protein class were analyzed separately by panther online tool. The heat maps of the top 10 dysregulated genes were generated in Prism 9.0.

\section{Results and Discussion}

To determine whether or not exposure to chlorpyrifos and/or cypermethrin cause any change in the expression profile of pulmonary genes in mice model, the transcriptomic analysis was performed for samples from all the groups using microarray technique. The genes that displayed a 12 folds dysregulation were considered. A total of 365 genes were dysregulated following exposure to chlorpyrifos, cypermethrin and their mixture. Treatment with chlorpyriphos upregulated 194 genes and downregulated 171 genes whereas cypermethrin treatment caused upregulation of 171 genes and downregulation of 152 genes while their combination upregulated 176 genes and downregulated 146 genes (minimum cut off of $12 \mathrm{log}$ fold change) (Fig 1A). The gene overlap study between differentially expressed genes (DEG) in all the groups showed 241 commonly expressed genes whereas chlorpyrifos, cypermethrin and their mixture showed 67, 32 and 13 DEG's respectively (Fig 1B). We have earlier reported that fipronil exposure induces the lung damage and alters the pulmonary transcriptomic profile in mice ${ }^{[36]}$.

Further, we selected top 10 DEG's for the identification of candidate genes responsible for lung damage. The gene expression and heat map along with their functional significance of these genes from microarray as has been presented in Figure 2. Protein-protein interaction (PPI) network was also generated for these genes using STRING online program on the basis of co-expression, co-occurrence and molecular function (combined score $>0.4 ; \mathrm{K}$ means clustering=3) (Fig 3). The PPI clustered Atp5g2, Cox6a1, Tpt1, Hint 1, Fau, Rps 27 , Fth 1 and Rplp0 while strong coexpression and co-occurance was depicted for Sftpd and Sftpal. Microarray data revealed dysregulation of mRNA expression of Atp5g2, Cox6al, Tpt1, Hint1, Fau, Rps27, Fth1, Rplp0, Sftpd, and Sftpal in all treatments groups.

Gene ontology study revealed that Cox6a1, which is a mitochondrial complex IV (Fig 3A-C) and Atp5g2 that play vital role in mitochondrial functioning. There was downregulation of Atp5g2 (-14.22, -13.75 and -13.73) and Cox6a1 (-14.91, -14.65 and -14.80$)$ following the exposure to chlorpyrifos, cypermethrin and their combination, respectively (Table 1). Cox6a1 and Atp5g2 are associated with mitochondrial dysfunction and are under expressed in thyroid cancer [37] and clear cell renal cell carcinoma [38], respectively. Pulmonary surfactant-associated protein D (Sftpd) and Pulmonary surfactant-associated protein A (Sftpal) contributes to the lung defence against inhaled organisms and toxins beside modulating leukocyte action in immune system. Exposure to chlorpyrifos, cypermethrin and their combination downregulated the pulmonary expression of 
Sftpd (-14.30, 14.15 and -14.46) and Sftpal (-14.10, 14.26 and -14.46) (Table 1). The expression of these pulmonary surfactant-associated proteins is inversely correlated with lung cancer progression ${ }^{[39,40]}$. Further, exposures simultaneously downregulated the Tptl (-14.79, -14.52 and -14.40) which have a novel role as the negative regulator of autophagy ${ }^{[41]}$. There was downregulation of FTHI $(-14.83,-14.52$ and 14.64) and Hint1 (-14.6, -14.39 and -14.47) following the exposure to chlorpyrifos, cypermethrin and their combination, respectively (Table 1). Under expression of FTHI has close association to tumorigenesis in breast cancer and colorectal carcinoma, suggesting a tumor-suppressive role ${ }^{[42] . ~ S i m i l a r l y ~}$ Hint1 is a tumor suppressor gene that inhibits oncogenic factors and enhances the expression of p53 and Bax with the down expression of $\mathrm{Bcl} 2$, an apoptotic inhibitor to regulate apoptotic pathways ${ }^{[43]}$. Previously available data suggest decline in hint1 expression may lead to cancer ${ }^{[44]}$.

Ribosomal $\mathrm{P}$ complex consists of the acidic ribosomal $\mathrm{P}$ (RPLP) proteins $R P L P O, R P L P 1$ and $R P L P 2$ and recruits translational factors to facilitate protein synthesis. Exposure to chlorpyrifos, cypermethrin and their combination downregulated the pulmonary expression of Rplp0 (-14.46, -
12.71 and -14.00) (Table 1). Reduced expression of RplpO causes cell cycle arrest in gastric cancer cells ${ }^{[45,46]}$. FAU encodes a ubiquitin-like protein called FUBI with ribosomal protein $\mathrm{S} 30$ as a carboxy-terminal extension and is a proapoptotic regulatory gene. There was downregulation of Fau $(-14.72,-14.47$ and -14.63$)$ and Rps27 (-14.85, -14.60 and 13.92) following the exposure to chlorpyrifos, cypermethrin and their combination, respectively (Table 1). Its downregulation has been reported in prostate and ovarian tumors and are strongly associated with poor prognosis in breast cancer [47]. Rps27, also called metallopanstimulin-1 (MPS-1), play important role in regulation of the mitotic checkpoint, spindle assembly and sister chromatid biorientation ${ }^{[48]}$. Its role in mitosis suggest that a decline in the expression RPS27 may cause mitotic check point dysfunction and chromosome alignment defect ${ }^{[49]}$. Data taken together indicate that long term dietary exposures to chlorpyrifos and cypermethrin individually or in combination downregulated the mRNA expression of Atp5g2, Cox6a1, Tpt1, Hint1, Fau, Rps27, Fth1, Rplp0, Sftpd, and Sftpa1 in the lung of mice.

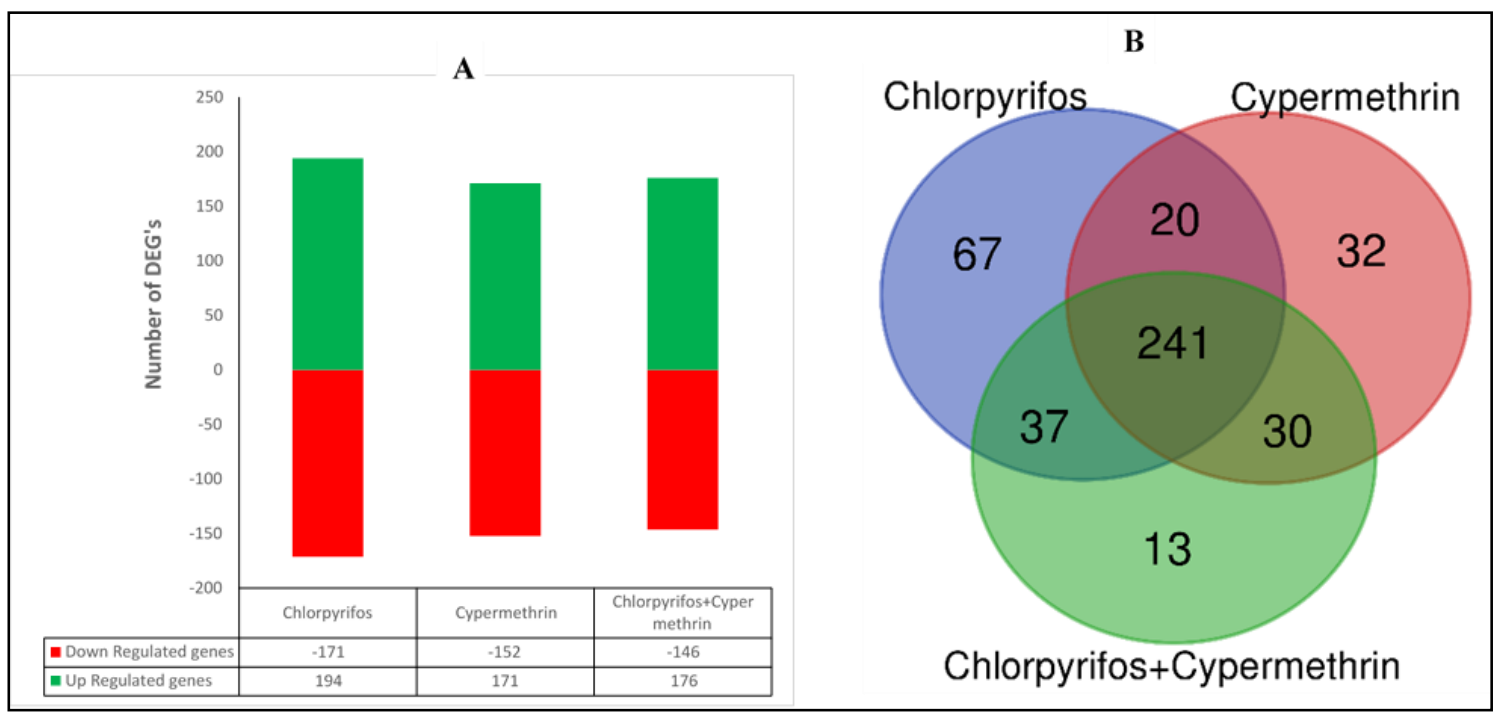

Fig 1: Global View (A) Venn diagram (B) of differentially expressed genes ( cut off of 12 log fold change) following exposure to Chlorpyriphos, Cypermethrin and their combination.

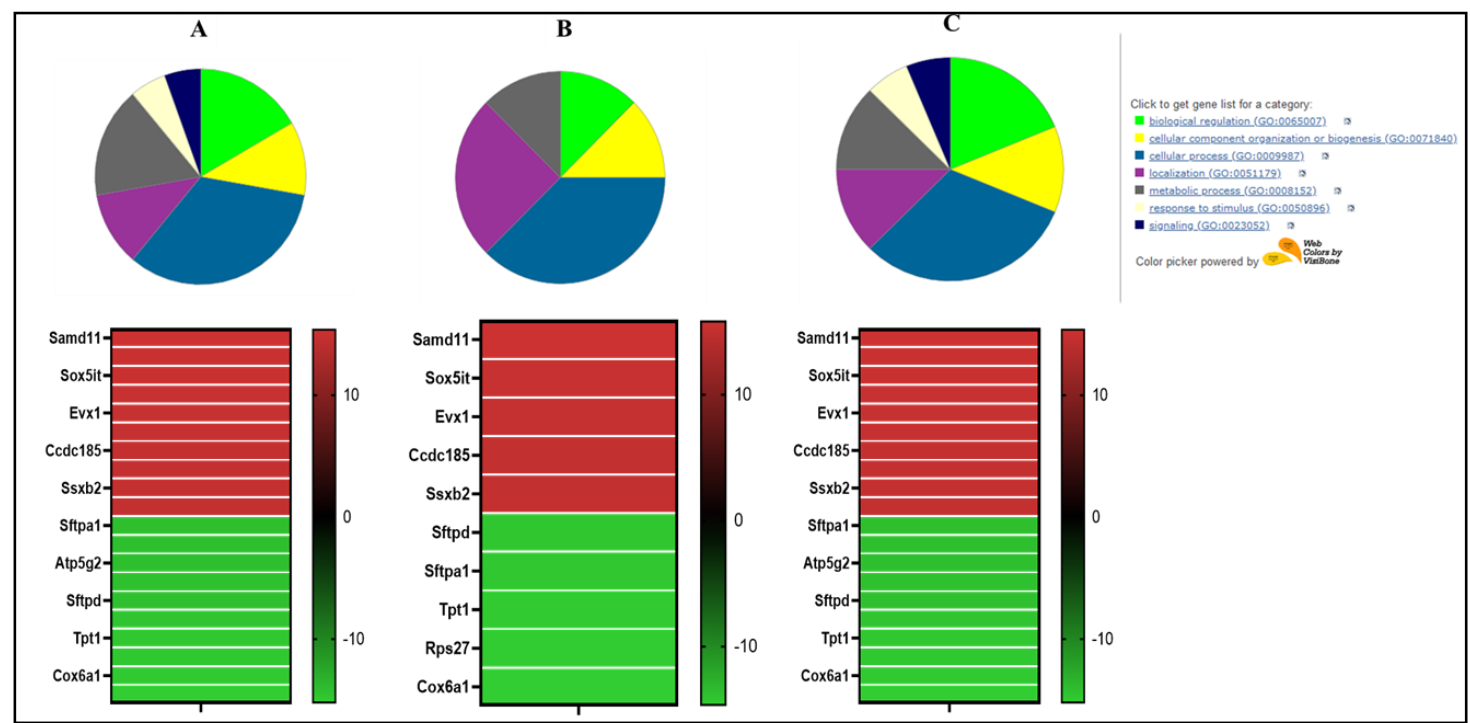

Fig 2: (a) Biological significance and Heat Map of Top 10 DEG's following exposure to Chlorpyriphos (A), Cypermethrin (B) and their combination (C). 


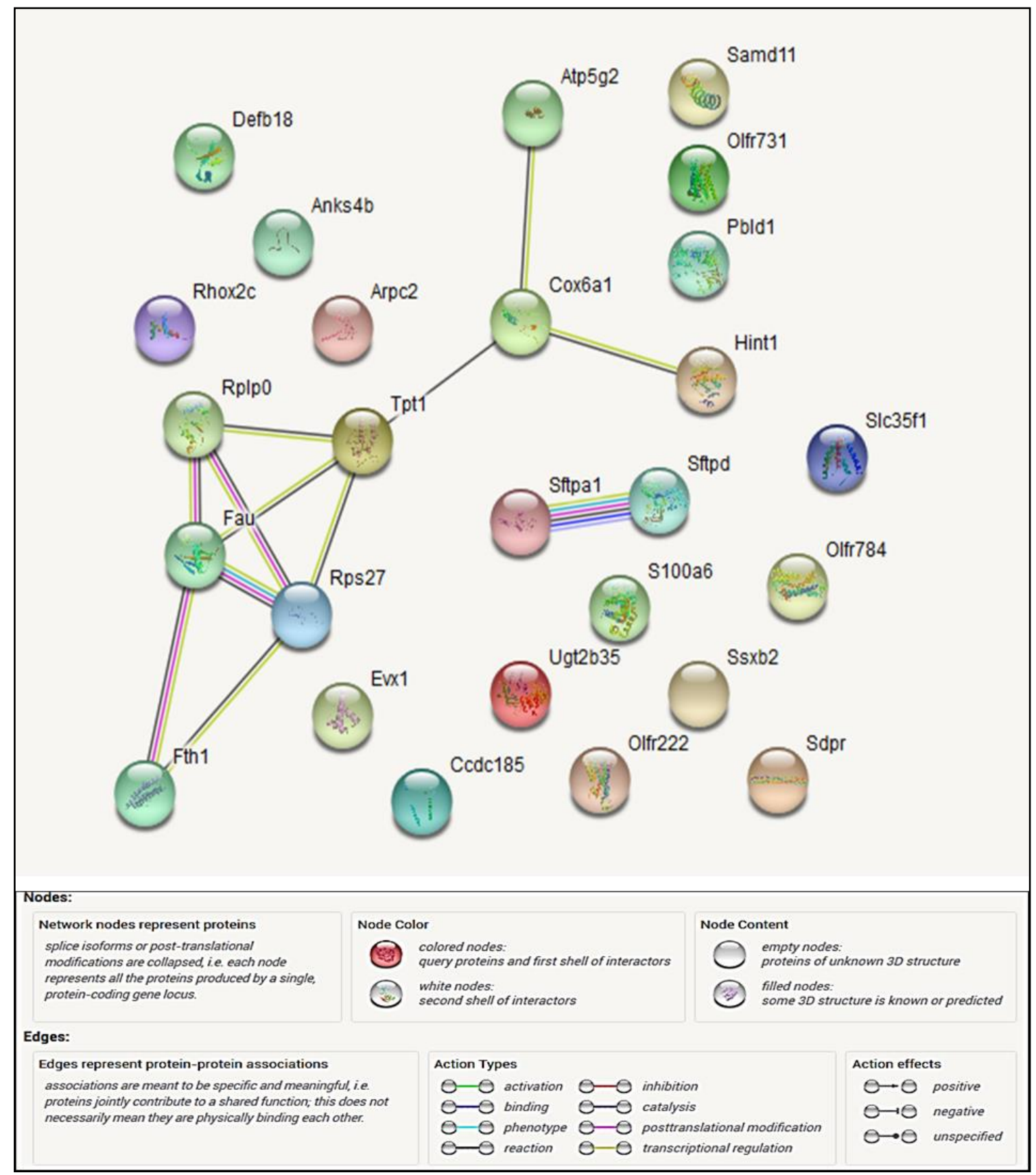

Fig 3: PPI network of top 10 DEGs following exposure to Chlorpyriphos, Cypermethrin and their combination.

Table 1: $\log 2$ fold change of Top 10 differentially expressed genes in various treatment groups,

\begin{tabular}{|c|c|c|c|c|c|}
\hline \multicolumn{2}{|c|}{ Chlorpyrifos } & \multicolumn{2}{c|}{ Cypermethrin } & \multicolumn{2}{c|}{ Chlorpyrifos+Cypermethrin } \\
\hline Name of genes & Log2 Fold change & Name of Gene & Log2 Fold change & Name of gene & Log2 Fold change \\
\hline Samd11 & 15.35 & Samd11 & 15.79 & Samd11 & 15.65 \\
\hline Sox5it & 15.00 & Sox5it & 15.33 & Sox5it & 15.27 \\
\hline Evxl & 14.77 & Evxl & 15.15 & Evxl & 14.82 \\
\hline Ccdc185 & 14.62 & Ccdc185 & 14.99 & Ssxb2 & 14.76 \\
\hline Ssxb2 & 14.59 & Ssxb2 & 14.91 & Atp5g2 & -13.73 \\
\hline Sftpa1 & -14.10 & Sftpd & -14.15 & Sftpal & -13.86 \\
\hline Atp5g2 & -14.22 & Sftpal & -14.26 & Sftpd & -14.46 \\
\hline Sftpd & -14.30 & Tpt1 & -14.52 & Tpt1 & -14.40 \\
\hline Tpt1 & -14.79 & Rps27 & -14.60 & Hint1 & -14.47 \\
\hline Cox6al & -14.91 & Cox6a1 & -14.65 & Cox6al & -14.80 \\
\hline
\end{tabular}

\section{Conclusion}

In this study, we have identified the differentially expressed pulmonary genes following the chronic dietary exposure to chlorpyrifos and/or cypermethrin. PPI showed that Atp5g2, Cox6a1, Tpt1, Hint1, Fau, Rps27, Fth1 and Rplp0 forms a network with each other whereas Sftpd and Sftpal are coexpressed. Data taken together suggest that exposure to chlorpyrifos and/or cypermethrin may induce lung damage via dysregulating the expression of Atp5g2, Cox6a1, Tpt 1 , Hint1, Fau, Rps27, Fth1, Rplp0, Sftpd and Sftpa.. The 
findings of current study have significance as farm workers get frequent exposures to the cocktail of these pesticides in field situations.

\section{References}

1. Limbore NV, Khillare SK. An analytical study of Indian agriculture crop production and export with reference to wheat. Review and Research 2015;4(6):1-8.

2. Abhilash PC, Singh N. Pesticide use and application: an Indian scenario. Journal of Hazardous Materials 2009;165(1-3):1-12.

3. Pandit AA, Gandham RK, Mukhopadhyay CS, Verma R, Sethi RS. Transcriptome analysis reveals the role of the PCP pathway in fipronil and endotoxin-induced lung damage. Respiratory research 2019;20(1):1-16.

4. Schreinemachers P, Tipraqsa P. Agricultural pesticides and land use intensifcation in high, middle and low income countries. Food Policy 2012;37(6):616-626.

5. Agnihotri NP, Gajbhiye VT, Kumar M, Mohapatra SP. Organochlorine insecticide residues in Ganga river water near Farrukhabad, India. Environmental Monitoring and Assessment 1994;30(2):105-112.

6. Sharma A, Kumar V, Bhardwaj R, Thukral AK. Seed presoaking with 24-epibrassinolide reduces the imidacloprid pesticide residues in green pods of Brassica juncea L. Toxicological \& Environmental Chemistry 2017;99(1):95-103.

7. Lee I, Eriksson P, Fredriksson A, Buratovic S, Viberg H. Developmental neurotoxic effects of two pesticides: behavior and neuroprotein studies on endosulfan and cypermethrin. Toxicology 2015;335:1-10.

8. Abraham E. Neutrophils and acute lung injury. Critical Care Medicine 2003;31:195-S199

9. Arafa MH, Mohamed DA, Atteia HH. Ameliorative effect of N-acetyl cysteine on alpha-cypermethrin-induced pulmonary toxicity in male rats. Environmental toxicology 2015;30(1):26-43.

10. Yurumez Y, Ikizceli I, Sozuer EM et al. Effect of inteleukin-10 on tissue damage caused by organophosphate poisoning. Basic Clin Pharmacol Toxicol 2007;100:323-7.

11. Solati A, Tavasoly A, Koohi $M$ et al. Effects of dermalexposure to chlorpyrifos on liver and brain structures and biochemical parameters in rabbits 2012;21:1211-1217.

12. Morowati M. Inhalation toxicity studies of Thimet (Phorate) in the male swiss albino mouse, Mus musculus: II. Lung histopathology, pseudocholinesterase level and haematological studies. Environmental Pollution 1998;103:309-15.

13. Sethi RS, Schneberger D, Charavarymath C, Singh B. Pulmonary innate inflammatory responses to occupational contaminants of farming. Cell and Tissue Research 2017;367(3):627-42

14. Shaikh NI, Sethi RS. Exposure to chlorpyrifos and cypermethrin alone or in combination induces developmental abnormalities and lung damage in animal models: A review. Journal of Entomology and Zoology Studies 2020;8(5):1923-1928

15. Pandit AA, Mukhopadhyay CS, Verma R, Singh B, Sethi RS. Expression of TLR-9 and IL-1 $\beta$ following concomitant exposure to imidacloprid and endotoxin. Pesticide Research Journal 2017;29(2):243-50.

16. Pandit AA, Choudhary S, Verma R, Singh B, Sethi RS.
Imidacloprid induced histomorphological changes and expression of TLR-4 and TNF $\alpha$ in lung. Pesticide Biochemistry and Physiology 2016;131:9-17.

17. Merkowsky K, Sethi RS, Gill JPS, Gill BS. Fipronil induces lung inflammation in vivo and cell death in vitro. Journal of Occupational Medicine and Toxicology 2016;11:10.

18. Pandit AA, Sethi RS. Pulmonary expression of Pla2g5 during lung damage in mice induced by fipronil and lipopolysaccharide interaction. Journal of Applied and Natural Science 2019;11(2):285-90.

19. Pandit AA, Mukhopadhyay CS, Verma R, Sethi RS. Fipronil induced VCAM-1 expression in lungs of mice. Asian Journal of Microbiology, Biotechnology and Environmental Science 2019;21 (Feb Suppl):S265-268

20. Tewari Anita, Sethi RS, Banga HS, Singh Baljit, Gill JPS. Concomitant effect of low dose of lindane and intranasal lipopolysaccharide on respiratory system of mice. Human Experimental Toxicology 2017;36(11):1201-11.

21. Kaur Sandeep, Mukhopadhyay CS, Sethi RS. Chronic exposure to indoxacarb and pulmonary expression of TLR-9 in mice. Veterinary World 2016;9(11):1282-86.

22. Kaur Sandeep, Mukhopadhyay CS, Arora JS, Sethi RS. Indoxacarb interaction alters immunotoxic and genotoxic potential of endotoxin. Journal of Pesticide Science 2016;41(3):65-70.

23. Chougule AA, Sethi RS, Schneberger D, Brar RS. Chlorpyriphos induces lung inflammation and alters response to $\mathrm{E}$. coli lipopolysaccharide challenge. The FASEB Journal 2013;27:11166.17.

24. Geetika, Sunil BV, Mukhopadhyay CS, Verma R, Sethi RS. Pulmonary expression of MYCN mRNA following exposure to 2,4-D with or without endotoxin challenge. Indian Journal of Animal Sciences 2019;89(11):1217-20.

25. Geetika, Sunil BV, Mukhopadhyay CS, Verma R, Sethi RS. Chronic dietary exposures of 2,4-D alter the pulmonary expression of MYC-N. Indian Journal of Veterinary Anatomy 2019;31(1):59-61.

26. Verma G, RS Sethi. Study of ethion and lipopolysaccharide interaction on lung in a mouse model. Laboratory Animal Research, BMC, Springer 2020;36:22.

27. Verma G, Mukhopadhyay CS, Verma R, Singh B, Sethi RS. Long-term exposures to ethion and endotoxin cause lung inflammation and induce genotoxicity in mice. Cell and Tissue Research 2019;375(2):493-505.

28. Verma Geetika, Verma Ramneek, Mukhopadhyay CS, Sethi RS. Acute ethion exposure alters expression of TLR 9 in lungs of mice. Indian Journal of Veterinary Anatomy 2016;28(1):40-43

29. Abraham E. Neutrophils and acute lung injury. Critical Care Medicine 2003;31:195-S199

30. Yurumez Y, Ikizceli I, Sozuer EM et al. Effect of inteleukin-10 on tissue damage caused by organophosphate poisoning. Basic Clin Pharmacol Toxicol 2007;100:323-7.

31. Yavuz Y, Kaya E, Yurumez Y et al. Technetium-99m diethylenetriaminepentaacetic acid radioaerosol scintigraphy in organophosphate induced pulmonary toxicity: experimental study. Clinical Toxicology 2008;46:711-5.

32. Costa, LG, Giordano G, Guizzetti M, Vitalone A. Neurotoxicity of pesticides: a brief review. Frontiers in 
Bioscience 2008;13:1240-1249.

33. Flaskos J, Harris W, Sachana M, Munoz D, Tack J, Hargreaves AJ et al. The effects of diazinon and cypermethrin on the differentiation of neuronal and glial cell lines. Toxicology and Applied Pharmacology 2007;219:172-80

34. Abdelhafidh K, Mhadhbi L, Mezni A, Badreddine S, Beyrem H, Mahmoudi E et al. Protective effect of Zizyphus lotus jujube fruits against cypermethrin-induced oxidative stress and neurotoxicity in mice. Biomarkers. 2018;23(2):167-73.

35. Nazki M, Sethi RS. Pulmonary Expression of TNFFollowing Exposure to Mixture of Chlorpyriphos and Cypermethrin with or without Endotoxin. Indian Journal of Veterinary Anatomy 2019;31(2):148-150.

36. Pandit AA, Gandham RK, Mukhopadhyay CS, Verma R, Sethi RS. Transcriptome analysis reveals the role of the PCP pathway in fipronil and endotoxin-induced lung damage. Respiratory research 2019;20(1):1-16.

37. Kumari S, Adewale R, Klubo-Gwiezdzinska J. The Molecular Landscape of Hürthle Cell Thyroid Cancer Is Associated with Altered Mitochondrial Function-A Comprehensive Review. Cells 2020;9(7):1570.

38. Brüggemann M, Gromes A, Poss M, Schmidt D, Klümper N, Tolkach Y et al. Systematic analysis of the expression of the mitochondrial ATP Synthase (Complex V) subunits in clear cell renal cell carcinoma. Translational oncology 2017;10(4):661-8.

39. Ishii $\mathrm{T}$, Hagiwara $\mathrm{K}$, Ikeda $\mathrm{S}$, Arai $\mathrm{T}$, Mieno $\mathrm{MN}$, Kumasaka $\mathrm{T}$ et al. Association between genetic variations in surfactant protein $\mathrm{d}$ and emphysema, interstitial pneumonia, and lung cancer in a Japanese population. COPD 2012;9:409-416.

40. Yamaguchi H, Soda H, Nakamura Y, Takasu M, Tomonaga N, Nakano H et al. Serum levels of surfactant protein $\mathrm{D}$ predict the anti-tumor activity of gefitinib in patients with advanced non-small cell lung cancer. Cancer Chemotherapy and Pharmacology 2011;67:331338.

41. Bae SY, Byun S, Bae SH, Min DS, Woo HA, Lee K et al. TPT1 (tumor protein, translationally-controlled 1) negatively regulates autophagy through the BECN1 interactome and an MTORC1-mediated pathway. Autophagy 2017;13(5):820-33.

42. Funauchi Y, Tanikawa C, Lo PH, Mori J, Daigo Y, Takano A et al. Regulation of iron homeostasis by the p53-ISCU pathway. Scientific reports 2015;5:16497.

43. Weiske J, Huber O. The histidine triad protein Hint1 triggers apoptosis independent of its enzymatic activity. Journal of Biological Chemistry 2006;281(37):27356-66.

44. Bao T, Ke Y, Wang Y, Wang W, Li Y, Wang Y et al. Taraxasterol suppresses the growth of human liver cancer by upregulating Hint1 expression. Journal of Molecular Medicine 2018;96(7):661-72.

45. Teller A, Jechorek D, Hartig R, Adolf D, Reißig K, Roessner A et al. Dysregulation of apoptotic signaling pathways by interaction of RPLP0 and cathepsin X/Z in gastric cancer. Pathology-Research and Practice 2015;211(1):62-70.

46. Artero-Castro A, Perez-Alea M, Feliciano A, Leal JA, Genestar M, Castellvi J et al. Disruption of the ribosomal $\mathrm{P}$ complex leads to stress-induced autophagy. Autophagy 2015;11(9):1499-519.

47. Perina D, Korolija M, Hadžija MP, Grbeša I, Belužić R,
Imešek M et al. Functional and structural characterization of FAU gene/protein from marine sponge Suberites domuncula. Marine drugs 2015;13(7):4179-96.

48. Sliedrecht T, Zhang C, Shokat KM, Kops GJ. Chemical genetic inhibition of Mps1 in stable human cell lines reveals novel aspects of Mps1 function in mitosis. PloS one 2010;5(4):e10251.

49. Jelluma N, Brenkman AB, McLeod I, Yates III JR, Cleveland DW, Medema RH, Kops GJ. Chromosomal instability by inefficient Mps1 auto-activation due to a weakened mitotic checkpoint and lagging chromosomes. PloS one 2008;3(6):e2415. 